\title{
Diacronie
}

Studi di Storia Contemporanea

$\mathrm{N}^{\circ} 15,3 \mid 2013$

Spazi, percorsi e memorie

\section{De la confesionalidad a la tolerancia: del derecho civil a la libertad religiosa en la España del último franquismo}

Romina De Carli

\section{(2) OpenEdition \\ Journals}

Edición electrónica

URL: http://journals.openedition.org/diacronie/466

DOI: $10.4000 /$ diacronie.466

ISSN: 2038-0925

Editor

Association culturelle Diacronie

Referencia electrónica

Romina De Carli, « De la confesionalidad a la tolerancia: del derecho civil a la libertad religiosa en la España del último franquismo », Diacronie [En línea], № 15,3 | 2013, documento 6, Puesto en línea el 01 octubre 2013, consultado el 21 abril 2019. URL : http://journals.openedition.org/diacronie/466 ; DOI : 10.4000/diacronie.466 


\title{
Diacronie
}

6/

\section{De la confesionalidad a la tolerancia: del derecho civil a la libertad religiosa en la España del último franquismo}

\author{
Romina DE CARLI*
}

En el presente artículo se analizan las repercusiones que el debate conciliar sobre libertad religiosa tuvo en la España del último franquismo. La tesis que se pretende sostener gira alrededor de la importancia que tuvo la constitucionalización de un derecho civil a la libertad religiosa para el proceso de democratización del régimen y para la evolución de las relaciones Estado-Iglesia en España, que tuvieron lugar después de la muerte de Franco.

\section{Introducción}

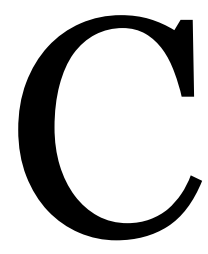

omo explica Guy Hermet, la incorporación a partir de 1953 del Opus Dei a las élites políticas de orientación católica, si por un lado favoreció el desarrollo económico de España, por el otro contribuyó a agudizar la crisis política y social de la dictadura ${ }^{1}$. Por otra parte, Samuel Huntington demuestra que a raíz del Concilio Vaticano II la Iglesia católica desarrolló un papel muy importante en el proceso de transición al postfranquismo². De hecho, mediada la década de 1960, fue la Iglesia católica aunque no el Opus Dei - quien tomó gradualmente distancia del régimen

\footnotetext{
${ }^{1}$ HERMET, Guy, Los católicos en la España franquista. II. Crónica de una dicatadura, Madrid, Siglo XXI de España, 1986, pp. 299-322.

2 HUNTINGTON, Samuel P., La tercera ola. La democratización a finales del siglo XX, Barcelona, Paidós, 1994, pp. 53, 76-79.
} 
franquista convirtiéndose en uno de los factores que, desde el interior, vehicularon la democracia.

Con el presente artículo se pretende arrojar más luz sobre un punto crucial del paso de una confesionalidad excluyente a otra incluyente, analizando las repercusiones que tuvo en España la declaración conciliar sobre libertad religiosa, estudiando la postura que el episcopado español mantuvo durante el debate conciliar sobre la Dignitatis humanæ, así como describiendo el proceso de modificación del artículo 6 del Fuero de los Españoles y la publicación de la Ley Orgánica reguladora del ejercicio del derecho civil en materia religiosa. Las hipótesis que tomamos en cuenta para explicar el origen de la conflictividad Iglesia-Estado del último lustro del franquismo, son el interés internacional de la Santa Sede en aceptar el derecho civil a la libertad religiosa y la maniobra de adaptación del episcopado español a la Dignitatis humanæ. Adaptación que tendrá, entre sus resultados, una posible tergiversación en la traducción al español de la Dignitatis humanæ.

\section{El debate conciliar sobre el derecho civil a la libertad religiosa}

La Dignitatis humanæ representa la piedra miliar de la presencia sociopolítica de la Iglesia católica en el mundo contemporáneo, pudiendo considerarse como el manifiesto más lúcido de la aceptación de la modernidad por parte de la doctrina católica. Admitir la existencia de un derecho civil a la libertad religiosa para todos, fue uno de los pasos más importantes que dio la Iglesia para dialogar con las democracias contemporáneas y evitar la marginación del fenómeno religioso a la esfera privada3. A ello había llegado después de una larga reflexión doctrinal que le permitió finalmente conjugar el concepto católico de dignidad humana con el que había elaborado las revoluciones liberales del siglo XX. La Revolución Francesa, así como la formación y consolidación de movimientos obreros de inspiración socialista, habían planteado a la Iglesia el problema de la autonomía e independencia del

3 GAUCHET, Marcel, La religion dans la démocratie, Paris, Gallimard, 1998, pp. 41-82; BAUBÉROT, Jean, «La Laïcité et les mutations du religieux chretièn et du politique au XXème siècle», in Cristianesimo nella storia, 22, 2001, pp. 633-657. 
Estado y de la Sociedad Civil respecto a la autoridad espiritual de la jerarquía eclesiástica. La defensa de la confesionalidad del Estado y la promoción de la militancia católica fueron las coordenadas de la acción política de la Iglesia durante la época liberal. Sin embargo, la gradual consolidación de regímenes democráticos y el proceso de secularizacion del Estado, empujaron a la Iglesia a reflexionar sobre la confesionalidad y la función que el Estado podía y tenía todavía que ejercer de cara a la profesión religiosa de la sociedad.

La política concordataria que la Santa Sede llevó a cabo en Europa en el período de entreguerras y en los primeros años de la Guerra Fría constituye un eslabón importante del proceso de separación entre Iglesia y Estado que, a comienzos del siglo XX, había empezado de manera irreversible en Francia. A pesar de su mayor propensión hacia los totalitarismos de derecha, la Santa Sede no se había olvidado de preservar la independencia de la Iglesia y de la comunidad católica de una posible absorción por el Estado. El reconocimiento de la Acción Católica en los Concordatos con Italia, Alemania y España - de 1929, 1933 y 1953 respectivamente - respondía claramente a este objetivo. Durante el primer tercio del siglo XX cuando la Iglesia fue descubriendo la función de presión socio-política que el asociacionismo católico podía desarrollar frente al Estado para defender las libertades y los intereses de la Iglesia. Sin embargo, y para evitar una pérdida de control de la jerarquía sobre el laicado católico, desde la encíclica Mystici corporis de Pío XII (1943) el magisterio había dejado bien claro que a los fieles les estaba totalmente vedado «traspasar de cualquier modo el orden de las cosas creadas e invadir erróneamente lo divino»4. Un límite que Pablo VI reiteraba durante el Concilio Vaticano II, fijando en la encíclica Ecclesiam suam (1964) los principios que debían inspirar la constitución Lumen Gentium sobre la Iglesia. Al respecto, el Pontífice recordaba a los fieles la importancia de «aprender diligentemente a distinguir entre los derechos y las obligaciones que les corresponden por su pertenencia a la Iglesia y aquellos otros que les competen como miembros de la sociedad humana». Discriminación necesaria para luego «acoplarlos armónicamente»5 según los criterios de la conciencia cristiana. Ese mismo

4 PÍO XII, Mystici corporis, Bilbao, Mensajero, 1966, p. 63.

5 Lumen Gentium: 36 en URL: 
principio de obediencia jerárquica inspiraría también la declaración conciliar Dignitatis humanæe sobre libertad religiosa que, solo por abdicar la confesionalidad del Estado, contribuyó a la democratización de las relaciones entre Estado, Iglesia y Sociedad.

El tema de la libertad religiosa fue central para el aggiornamento conciliar desde las fases preparatorias del Vaticano II. Tanto Juan XIII como Pablo VI habían intuido lo fundamental que era admitir un derecho civil a la libertad religiosa para fomentar el necesario diálogo entre católicos y cristianos separados y para redefinir el concepto de universalidad de la Iglesia católica. No obstante, los sectores más conservadores de la Curia y del Concilio no dejarían de hostigar la labor del Secretariado para la Unidad entre los cristianos. Tanto que el primer borrador del De libertate se presentó por primera vez al aula solamente a finales de la segunda sesión del Vaticano II (1963). Su votación preliminar se llevó a cabo durante la sesión de 1964 siendo sólo en la cuarta y última sesión cuando Pablo VI lograría crear un consenso mayoritario sobre aquella delicada materia. Los meses entre las sesiones de 1963-1964 representan un punto de no retorno en este tortuoso camino, porque el Secretariado para la Unidad entre los Cristianos reelaboró el De libertate enfocando el derecho a la libertad religiosa única y exclusivamente desde una perspectiva humana y social. Para la Iglesia, el derecho a la libertad religiosa que el concilio podía y tenía que admitir no era otro que el derecho civil del hombre a actuar conforme a su conciencia así como a no tener que actuar en contra de ella ${ }^{6}$.

Era en el otoño de 1964 cuando -pese al duro ataque del sector más intransigente ${ }^{-}$- el De libertate era aceptado finalmente como base para un futuro documento conciliar. La grieta que aquella 'emboscada' abrió en el seno de la misma Iglesia obligaba a Pablo VI a tomar en sus manos las riendas del concilio, para evitar que una dilación del mismo llevara a la Santa Sede a

\footnotetext{
< http://www.vatican.va/archive/hist_councils/ii_vatican_council/documents/vatii_const_19641121_lumen-gentium_sp.html $>$ [consultado el 5 de mayo de 2013].

6 VILLANOVA, Evangelista, L'intersessione (1963-1964), in MELLONI, Alberto, Storia del Concilio Vaticano II. Concilio di transizione. Il quarto periodo e la conclusione del concilio (settembre-dicembre 1965), Bologna, Il Mulino, 1998, pp. 367-383, 402.

7 MICCOLI, Giovanni, Due nodi: la libertà religiosa e le relazioni con gli ebrei, in MELLONI, Alberto (a cura di), Storia del Concilio Vaticano II. Chiesa come comunione. Il terzo periodo e la terza intersessione (settembre 1963-settembre 1964), Bologna, Il Mulino, 1999, pp. 119-219.
} 
desperdiciar una coyuntura internacional muy favorable a su acción política en el mundo. En el otoño de 1965, el Secretariado para la Unidad entre los Cristianos enfrentaba la última sesión del Concilio con una pequeña ventaja respecto a sus adversarios. Pablo VI había sido invitado a presenciar en Nueva York la celebración del vigésimo quinto aniversario de fundación de la ONU. Una ocasión que el papa no quería dejar pasar en balde, sin demostrar que la Iglesia podía ser una pieza fundamental para la construcción de una paz duradera en el mundos. La intención era crear un clima de consenso que permitiera al De libertate superar la votación preliminar del 25 de septiembre. Para conseguir este objetivo, Pablo VI había optado por presentar aquel texto como perfectible en cuanto a su ortodoxia respecto a la doctrina católica acerca de la verdadera religión. $\mathrm{Y}$, una vez alcanzada la esperada mayoría de placet (1.997 contra 224 non placet), incorporaba al Secretariado para la Unidad entre los Cristianos dos personas de su total confianza para que dirigiesen el trabajo de revisión según las orientaciones pontificias. Revisado el documento en tiempo récord, a comienzos de octubre el anteproyecto de declaración ya había alcanzado un grado de definición más que aceptable. Para asegurar este resultado Pablo VI insistirá, en víspera de su viaje a Estados Unidos, en los tres puntos que obligatoriamente había que tener presentes para cualquier ulterior corrección del De libertate. A saber: la superioridad de la verdad católica, la obligación para el hombre de buscar dicha verdad y, por último, la continuidad entre el magisterio pontificio de sus antecesores y la renovada doctrina conciliar en materia de libertad religiosa. Revisado a la luz de estas puntualizaciones, el texto definitivo llegaba a manos de los padres conciliares el 22 de octubre de 1965 para ser finalmente aprobado durante la votación de la congregación pública de 7 de diciembre. A esas alturas solamente una minoría irreductible se había manifestado aún en contra de un derecho civil a la libertad religiosa ${ }^{10}$.

\footnotetext{
8 PABLO VI, Visita del Sumo Pontífice Pablo VI a la Organización de las Naciones Unidas. Discurso a los representantes de los Estados, en URL:

<http://www.vatican.va/holy_father/paul_vi/speeches/1965/documents/hf_pvi_spe_19651004_united-nations_sp.html $>$ [consultado el 5 de mayo de 2013].

9 Acta Synodalia Sacrosancti Concilii Vaticani II (AS), IV/1, pp. 434, 564.

10 SCATENA, Silvia, La fatica della libertà. L'elaborazione della dichiarazione "Dignitatis humaæ" sulla libertà religiosa del Vaticano II, Bologna, Il Mulino, 2003, pp. 459-558; ROUTHIER, Gill, Portare a termine l'operazione iniziata: la faticosa esperienza del quarto periodo, in MELLONI, Alberto (a cura di), Storia del Concilio Vaticano II. Concilio di
} 


\section{El episcopado español y la Dignitatis humanae}

Por lo que concierne a España, la principal consecuencia de la declaración conciliar sobre la libertad religiosa estriba en haber acelerado un proceso de reformas institucionales que el régimen tenía que emprender para integrarse en el contexto internacional de la época ${ }^{11}$. Para el ministro de Asuntos Exteriores, flexibilizar la confesionalidad del Estado reconociendo una mayor publicidad a los cultos no católicos, era la forma de demostrar, a los EE.UU. y a los países integrantes el Mercado Común, la buena disposición de España para adecuarse a los criterios institucionales de las democracias occidentales. Y que Fernando María Castiella propusiera la promulgación de un Estatuto para los no católicos antes de que el concilio Vaticano II estudiara el De libertate revelaba asimismo la vinculación de esta tímida apertura a una serie de objetivos de política exterior.

Castiella aprovechaba - pero sin éxito - la boda de don Juan Carlos de Borbón con la princesa Sofia de Grecia (ortodoxa) para presentar un primer proyecto de Estatuto para los no católicos. El interés de Juan XXIII y Pablo VI hacia el derecho civil a la libertad religiosa permitió finalmente al ministro español vencer las resistencias internas frente a un régimen de tolerancia religiosa. En concreto, tanto Falange como la jerarquía episcopal habían manifestado claramente su oposición a considerar el derecho de los no católicos al proselitismo como elemento constitutivo del más amplio derecho a la libertad religiosa. Los primeros, por temer que aquel derecho pudiera dar cobijo a alguna actividad de propaganda política; los segundos, por estimarlo contrario a las prerrogativas que el catolicismo tenía en tanto que religión mayoritaria y oficial. Ambos frentes intentarían así obstaculizar el debate sobre el Estatuto propuesto por Castiella: los detractores políticos, vinculando una eventual modificación de la confesionalidad del Estado español a las decisiones que el Concilio tomara acerca del De libertate y, los detractores eclesiásticos, haciendo

Transizione. Il quarto periodo e la conclusione del concilio (settembre-dicembre 1965), Bologna, Il Mulino, 2001, pp. 97-104.

${ }^{11}$ VIÑAS, Ángel, En las garras del águila. Los pactos con Estados Unidos, de Francisco Franco a Felipe González (1945-1995), Barcelona, Crítica, 2003 ;HERMET, Guy, op. cit., pp. 382-395. 
lo imposible para que el aula conciliar eximiera a España de aplicar la declaración sobre libertad religiosa ${ }^{12}$. El Concilio defraudaba sin embargo a los unos y a los otros. Una vez aprobada la Dignitatis humanæ, la propia confesionalidad del Estado obligó al régimen a modificar el artículo 6 del Fuero de los Españoles y a otorgar el derecho a la libertad religiosa a los no católicos.

Respecto al episcopado español, cabe destacar que el anacronismo de su formación teológica le había impedido responder crítica y adecuadamente a las necesidades de una sociedad profundamente transformada ${ }^{13}$. Tanto es así, que el argumento que dominó los informes enviados a Roma durante las fases preparatorias del Concilio había sido casi exclusivamente el relativo a los problemas pastorales generados por el indiferentismo religioso. No debe extrañar, por lo tanto, que los aires de renovación del Vaticano II desplazaran desde el principio a los obispos españoles. Quizá lo que sí puede llamar la atención es que fuese precisamente el cuestionado documento De libertate el que logró hacer mella en el monolitismo teológico de este episcopado hasta llevar a un reducido número de obispos a adoptar una postura más pragmática. Fue de hecho este posibilismo lo que, en el período de entre sesiones de 19631964 y 1964-1965, aglutinó al episcopado español alrededor de un "andamiaje argumental" que, aceptando la liberalización religiosa como un mal menor, permitió limitar las consecuencias de su aplicación a España. Muy verosímilmente, lo que favoreció todo eso fue, por un lado, la decisión del Consejo de Ministros de septiembre de 1964 de supeditar el Estatuto de Castiella a las decisiones del Vaticano II en materia de libertad religiosa y, por el otro, la capacidad del Secretariado para la Unidad entre los Cristianos de salir airoso de los ataques que el sector intransigente del concilio había dirigido contra el De libertate durante el otoño de 1964.

\footnotetext{
${ }^{12}$ Archivo del Ministerio de Asuntos Exteriores de Francia (AMAE-F), Europe-Espagne 19441970.

13 VILLANUEVA, Evangelista, Los "vota" de los obispos españoles después del anuncio del concilio Vaticano II, in LAMBERIGTS, Mathjias, SOETENS, Claude (eds.), À la veille du Concile Vatican II. Vota et réaction en Europe et dans le catholicisme oriental, Leuven, Bibliotheck van de Facultait der Godgeleerdheid, 1992, pp. 60-62; RAGUER, Hilari, Fuentes para la historia del Vaticano II: España, in GROOTAERS, Jan-Lodewijk, SOETENS, Claude (eds.), Sources locales de Vatican II. Symposium Leuven-Louvain la Neuve (13-15 X 1989), Leuven, Bibliotheck van de Facultait der Godgeleerdheid, 1990, pp. 82-83.
} 
Si se analizan las enmiendas presentadas al De libertate por los obispos españoles entre 1963 y 1965, se descubre que las argumentaciones críticas sobre el citado documento, en el período de entre sesiones de 1963-1964, siguen el planteamiento propuesto por monseñor Muñoyerro mientras que, en el período de 1964-1965, siguen el de monseñor Cantero Cuadrado. Lo que permite delinear claramente cuándo y cómo la jerarquía eclesiástica española cambió de rumbo decantándose finalmente por aceptar un derecho civil a la libertad religiosa. De hecho, si entre 1963 y 1964 la referencia al caso español sirvió para oponerse radicalmente a una declaración conciliar sobre el derecho civil a la libertad religiosa, fue entre 1964 y 1965 cuando - al quedar claro que el Concilio iba a aprobar el De libertate - la confesionalidad del Estado español se esgrimió como justificación para excluir el proselitismo del conjunto de derechos a la libertad religiosa.

De cara a la posibilidad de negociar con el Ministerio español de Asuntos Exteriores «el reglamento de las Confesiones disidentes» ${ }^{4}$, la jerarquía episcopal había entregado al Nuncio Apostólico en Madrid una reinterpretación del De libertate. Era para reiterar la posibilidad, allí defendida, de aplicar de manera discriminatoria el derecho a la libertad religiosa, por lo que monseñor Muñoyerro en 1964 había insistido en la necesidad de definir el concepto teológico de libertad religiosa que debía fundamentar el homólogo derecho civil. Desde su punto de vista, era imposible comparar la realidad religiosa de España con la que existía en Alemania o en los Estados Unidos' ${ }^{15}$. Y era para rematar esta opinión y destacar el interés político que empujaba al Vaticano II a pronunciarse favorablemente sobre el De libertate, que el vicario castrense preguntaba retóricamente si de verdad una organización como la ONU - que no tenía autoridad alguna en materia de fe - podía responsabilizarse del respeto universal de la libertad religiosa ${ }^{16}$.

En el otoño de 1964 aún se puede notar cierta unanimidad en la postura del episcopado español, siendo la incompetencia del Estado en materia religiosa y la autoridad de la Conferencia Episcopal para determinar el radio de aplicación del

14 CARCEL ORTÍ, Vicente, Actas de la Conferencia de Metropolitanos españoles (1921-1965), Madrid, BAC, 1994, p. 645.

${ }_{15}$ AS III/3, pp. 631-632.

${ }^{16}$ AS III/3, p. 632. 
derecho de los no católicos a profesar libremente su credo, las líneas argumentales comunes a una gran parte de los obispos ${ }^{17}$. Sin embargo, es precisamente durante la tercera sesión del Vaticano II cuando el monolitismo de la jerarquía eclesiástica española empieza a agrietarse. Y si por un lado monseñor del Campo y de la Bárcena y monseñor García Goldáraz no dejan de seguir el patrón ofrecido por monseñor Muñoyerro, es monseñor Cantero Cuadrado quien se aleja parcialmente de él centrándose en aquellos puntos del De libertate que pueden justificar el reconocimiento a los no católicos de un derecho "reducido" a la libertad religiosa.

En concreto, monseñor del Campo y de la Bárcena consideraba una desviación política el querer ensalzar el pluralismo religioso estigmatizando el catolicismo de Estado. Además, dado el carácter pastoral del Concilio, lamentaba que el Vaticano II no defendiera adecuadamente a los católicos frente a los otros cristianos, y le reprochaba la voluntad de imponer una libertad que podía perturbar la paz social de países monoconfesionales como España. Igual de mordaz que Muñoyerro, a la hora de reivindicar un margen de discrecionalidad en materia de libertad religiosa se preguntaba si Gran Bretaña y los Estados Unidos serían tan críticos con la intolerancia religiosa si sus sociedades estuviesen compuestas por un $98 \%$ de católicos ${ }^{18}$. Más conciso y directo había sido monseñor García Goldáraz, estimando que el Concilio se equivocaba al pensar que la aprobación del De libertate contribuiría a eliminar la discriminación religiosa en los países del área comunista. En su opinión, Por lo pronto, lo único que podía hacer era preparar el terreno para desmoronar la unidad católica de España ${ }^{19}$. Por su parte y consciente de que el De libertate estaba destinado a llegar a buen puerto, monseñor Cantero Cuadrado optaba por insistir en la legitimidad de un derecho reducido a la libertad religiosa para los no católicos. Desde su punto de vista, si la función del derecho a la libertad religiosa era la de favorecer el diálogo ecuménico y la paz entre los pueblos, resultaba jurídicamente correcto pedir a los no católicos que ejercieran su

19 AS III/2, p. 689. 
derecho respetando las exigencias del orden moral y del bien común de la sociedad mayoritariamente católica en la que vivían²0.

Fue este último enfoque el que acabó inspirando al episcopado español a partir del otoño de 1964. No hay que descartar el peso que pudo ejercer en esta reorientación la decisión de Pablo VI de incorporar, en el verano de 1963, al propio monseñor Montero Cuadrado en el Secretariado para la Unidad entre los Cristianos y de elevarle a la archidiócesis de Zaragoza en el verano de $1964^{21}$ A esas alturas, los prelados españoles todavía no habían perdido del todo las esperanzas de que la confesionalidad de España pudiese quedarse al margen del aggiornamento conciliar. La decisión del Consejo de Gobierno de 30 de septiembre, de supeditar el debate y aprobación del Estatuto de Castiella a las decisiones del Vaticano II sobre libertad religiosa, animó de hecho a los más conservadores a firmar las peticiones que se habían cursado al Tribunal Administrativo y al Consejo de Presidencia del Concilio, el 17 y 18 de noviembre, para demorar aún más la votación del De libertate. Al respecto, lo que parece interesante destacar no es tanto - o no es solo - que 9 obispos firmaran ambos documentos (entre ellos, monseñor Muñoyerro y monseñor del Campo y de la Bárcena), sino que el cardenal Quiroga Palacios se adhiriera solamente a la segunda. Esta adhesión se explicaría por la entrevista mantenida con Pablo VI, quien le había pedido que -como cardenal- le ayudara a crear en el episcopado español un clima de confianza hacia la constitucionalización de la libertad religiosa ${ }^{22}$. Obligados a rendirse a las circunstancias, fue a partir de 1964 cuando los obispos españoles empezaron a armar las argumentaciones necesarias para dirigir el derrumbe del nacionalcatolicismo.

Para favorecer un consenso lo más amplio posible hacia el De libertate ${ }^{23}$, el episcopado español envolvió el sistema tradicional de tolerancia con el nuevo concepto conciliar de libertad religiosa. El argumento que se esgrimió para impedir que se reconociera explícitamente el derecho de propaganda y proselitismo a favor de las confesiones no católicas, fue sostener que limitar la

\footnotetext{
${ }^{20}$ AS III/2, pp. 474-476.

${ }^{21}$ Archivo Ministerio Asuntos Exteriores de Francia (AMAE-F), Europe-Espagne 1944-1970 ; SCATENA, Silvia, op. cit., pp. $82,182-183$.

${ }_{22}$ Ibidem, pp. 299-300; COMÍN, Alfonso Carlos, «N’ayez pas peur de la liberté religieuse», in Temoignage Chrètien, 7 de enero de 1965.

23 SCATENA, Silvia, op. cit., p. 300.
} 
manifestación pública de un acto religioso interno no era lesivo ni de la dignidad humana ni, mucho menos, de la paz social. Para eso, los obispos españoles se habrían apoyado en los párrafos del De libertate que enumeraban los principios que el Estado tenía que respetar a la hora de justificar y definir jurídicamente el derecho civil a la libertad religiosa, estando -entre ellos- el de no alterar la convivencia pacífica y no perjudicar al bien común.

La intervención de monseñor Flores Martín refleja a la perfección esta línea de pensamiento. En su opinión, negar o cuando menos acotar el ejercicio público de la libertad religiosa de los no católicos no afectaba negativamente a la dignidad del hombre. En primer lugar, porque era posible hablar de una vertiente externa (pública) y otra interna (privada) del derecho a la libertad religiosa y, en segundo lugar, porque se podía todavía admitir un régimen de tolerancia hacia los no católicos en países de mayoría católica. Como explicaba de manera metafórica, la libertad civil en materia religiosa era como una prenda que sólo puede sentar bien cuando es de la talla apropiada, siendo para respetar las «proporciones» de la confesionalidad católica por lo que era necesario acotarla por el lado del proselitismo no católico ${ }^{24}$. Fue alrededor de este punto de vista que giraron las otras intervenciones del episcopado español (tanto del sector intransigente como del sector aperturista) sosteniendo la legitimidad del proselitismo no católico solo cuando se dirigiese a los «libere accedentibus» 25 y la necesidad de respetar la moral dominante como medida para salvaguardar la paz social 26 .

En estos términos se expresaron, entre otros, Morcillo González (Madrid), Cantero Cuadrado (Zaragoza), Enrique Tarancón (Oviedo), Hervás Benet (Ciudad Real) Jubany Arnau (Gerona) y Fernández-Conde (Córdoba). De manera especial, este último presentó el 22 de septiembre de 1965 una breve disertación escrita enfocando el derecho a la libertad religiosa desde las relaciones entre la autoridad civil y la Iglesia. Si se consideraba el catolicismo del Estado como el reconocimiento constitucional de un trato especial a la religión con más solera en la mentalidad y costumbres de una determinada sociedad, había que censurar cualquier equiparación - en cuanto a derechos - 
entre comunidades religiosas grandes y comunidades religiosas pequeñas, y considerar como legítimo el reducir a la esfera privada el derecho de las comunidades minoritarias a profesar $\mathrm{su} \mathrm{fe}^{27}$.

Por su parte, el sector más intransigente del episcopado español vertebraba su oposición al De libertate alrededor de la inmadurez doctrinal del documento, de su incompatibilidad con el magisterio pontificio y de su falta de vinculación a la Sagrada Escritura. Paradigmáticas habían sido las intervenciones del arzobispo de Tarragona y del obispo de Calahorra. El primero, reiterando la ilicitud de un derecho al proselitismo a favor de los no católicos y sosteniendo la facultad de los episcopados nacionales para decidir -junto a la Santa Sede- la oportunidad de modificar el trato reservado a los ciudadanos que profesaban una religión no oficial ${ }^{28}$. El segundo, considerando que el aula no debía rendirse a las presiones del mundo contemporáneo. Al tachar de oportunista la decisión conciliar de aprobar el derecho civil a la libertad religiosa, del Campo y de la Bárcena recordaba que el hombre no era titular de ningún derecho frente a Dios, que por derecho natural el Estado tenía que respetar la obligación del hombre de buscar la verdad y, por último, que el derecho natural de los católicos a la libertad religiosa no era compatible con el homólogo derecho civil que el Concilio quería otorgar a los no católicos 29.

Frente a la firme determinación del Secretariado para la Unidad entre los

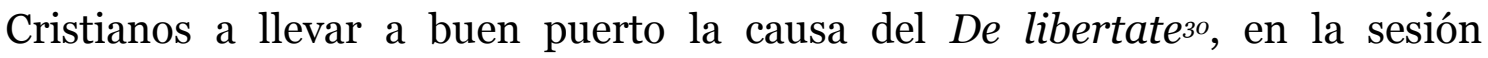
conciliar de 1965 algunos obispos jugaron su última baza dirigiéndose directamente al Pontífice. En primera instancia, monseñor Guerra Campos recomendaba al teólogo personal de Pablo VI los cinco puntos del De libertate que había que revisar si se querían sosegar las preocupaciones de un amplio espectro del aula conciliar ${ }^{3}$. En segunda instancia, el 17 de octubre un grupo de obispos recordaba al pontífice el interés que la Santa Sede había demostrado en 1953 por que en España hubiera un régimen de cristiandad, y procuraba convencerle de la conveniencia de incorporar al documento definitivo una nota

\footnotetext{
27 AS IV/2, p. 151.

${ }_{28}$ AS IV/1, pp. 209-210.

${ }_{29}$ AS IV/1, pp. 314-318.

30 AS IV/1, p. 317.

${ }^{31}$ SCATENA, Silvia, op. cit., pp. 536-537.
} 
interpretativa aduciendo el riesgo de que en España resurgiera un anticlericalismo de derechas ${ }^{32}$.

Para Pablo VI, sin embargo, la presencia internacional de la Santa Sede y la existencia de una Iglesia católica en los países de la órbita soviética tenían prioridad, ya que era allí -y no en España- donde se planteaba en toda su urgencia y gravedad el problema de un desarraigo social de la religión. En España, la confesionalidad del régimen franquista podía todavía contener tanto el irremediable proceso de secularización social como un eventual enfrentamiento político entre Iglesia y Estado.

No debe entonces extrañar que la traducción oficial al español de la Dignitatis humanæ se tergiversara precisamente en el párrafo que proclama el derecho de las comunidades religiosas a «ne impediatur in sua fide ore et scripto publice docenda atque testanda». En este punto, se optaba por sustantivar los gerundios docenda y testanda eligiendo para el verbo pasivo testāri el término profesión en lugar de la expresión ser testigo, y por transformar el adverbio publice en un adjetivo asociándolo solamente al mencionado término de profesión de la fe. El resultado era que -en lo que al proselitismo se refiere- a las comunidades no católicas se les reconocía «el derecho a no ser impedidas en la enseñanza y en la profesión pública, de palabra y por escrito, de su fe»33. Si se compara esta versión con las homólogas al italiano y al francés, más correcto, quizá, habría sido interpretar aquel párrafo considerando el derecho de las comunidades no católicas a no ser impedidas en la enseñanza y testimonio públicos de su credo. Se puede concluir afirmando que el objetivo de dicha manipulación no fue verosímilmente otro que el de justificar la disminución del derecho a la libertad religiosa de los no católicos. Al respecto, téngase en cuenta que la posterior Ley Orgánica sobre el derecho civil a la libertad en materia religiosa se inspiraría precisamente en aquella traducción de la Dignitatis humanæ.

32 IRIBARREN, Jesús, Papeles y memorias. Medio siglo de relaciones Iglesia-Estado en España (1936-1986), Madrid, BAC, 1992, pp. 259-264 y SCATENA, Silvia, op. cit., p. 533.

33 Para las citas, Dignitatis humanæ: 4 en URL: http://www.vatican.va/archive/hist_councils/ii_vatican_council/documents/vat-

ii_decl_19651207_dignitatis-humanae_sp.html [consultado el 7 de mayo de 2013]. 


\section{De la confesionalidad católica a la tolerancia religiosa}

El paso de una confesionalidad excluyente a otra incluyente no fue motivo de enfrentamiento entre la Iglesia y el Estado, pero sí entre los aperturistas y los integristas del propio régimen. Rivalidades que el Caudillo ya no era capaz de encauzar como antaño. Los inmovilistas no habían tardado en darse cuenta de que vincular el Estatuto de Castiella a las decisiones que el Concilio tomase acerca de la libertad religiosa, había sido una victoria pírrica. Y ello no porque la Dignitatis humanæe fuera más avanzada que el Estatuto de Castiella, sino porque, una vez actualizado el artículo 6 del Fuero de los Españoles según la nueva doctrina conciliar, el régimen tuvo que regular el derecho civil a la libertad religiosa de las minorías no católicas a través de una Ley Orgánica.

Un primer anteproyecto de ley había sido elaborado ya en el verano de 1966. Su corte era bastante progresista ya que regulaba incluso los polémicos derechos de propaganda, asociación y reunión. El régimen necesitaba en efecto convencer tanto a la Santa Sede como a los países del bloque occidental acerca de sus intenciones democratizadoras. Por eso, a comienzos del año siguiente el Gobierno enviaba el citado borrador a la Secretaria de Estado del Vaticano. La respuesta no hizo esperar, si bien la Santa Sede quiso dejar claro que habría dado su visto bueno al texto siempre y cuando el Consejo de Ministros lo aceptase sin modificaciones sustanciales34. Condición ésta que el régimen no atendería, puesto que el proyecto de ley que enviaría a las Cortes el 9 de marzo de 1967 sufriría unos cambios de mucho calado con respecto a la propuesta originaria. La supresión del artículo 12 sobre el derecho «d'etablir [...] des associations éducatives, culturelles, charitables et sociales»35 era una de las correcciones secundarias - según el entonces ministro de Justicia - detrás de las cuales se escondía el propósito de seguir utilizando la confesionalidad del Estado como barrera para impedir la legalización de una oposición política al régimen. Los legisladores distorsionaban así el sentido último de la Dignitatis humanæ. El derecho civil de los no católicos a la libertad religiosa, en el que

34 Archivo Ministerio Asuntos Exteriores de España (AMAE-E), Santa Sede-Renovado y AMAEF, Europe-Espagne, 1944-1970.

35 AMAE-F, Europe-Espagne, 1944-1970. 
había pensado el Consejo de Ministros, no miraba tanto a salvaguardar la esfera íntima del hombre de cualquier intromisión por parte del Estado como a proteger al Estado contra cualquier abuso que la sociedad civil pudiera cometer amparada por aquella misma libertad.

Como es conocido, el margen de acción de los procuradores en Cortes para intervenir en la revisión del articulado fue mínimo o casi nulo. El debate que se llevó a cabo en la Comisión de Leyes Fundamentales y Presidencia del Gobierno no tuvo otra función que la de limar asperezas para buscar un equilibrio entre los partidarios de una libertad escasamente limitada y los de una libertad fuertemente condicionada. Como había destacado Joaquín Bau al inaugurar los trabajos de la comisión, la actualización político-religiosa que se iba a efectuar con la aprobación de una Ley Orgánica reguladora del derecho civil de los no católicos a la libertad religiosa, no iba a afectar absolutamente los pilares del Estado franquista: ni a su confesionalidad ni a la unidad religiosa de la nación ${ }^{36}$.

A pesar de esas garantías, el sector más intransigente aprovechaba el primer turno de debate para cuestionar la decisión de la Ponencia de aceptar sólo quince de las doscientas quince enmiendas que los procuradores habían presentado a la totalidad del proyecto. Por eso el Sr. Yzurdiaga había juzgado como una auténtica pérdida de tiempo el tener que analizar un texto que no admitía modificación alguna. Estaba claro - desde su punto de vista - que para el Gobierno era más importante la integración internacional de España que salvaguardar la unidad interna. Con eso, y una vez aclarado que el tema de la libertad religiosa no había sido una ocurrencia de último minuto y que ya no era posible regular aquel derecho a través de un Estatuto, los procuradores pasaron a ocuparse del meollo de la cuestión. Es decir, la compatibilidad entre derecho a la libertad religiosa para los no católicos y Estado confesional37. Eran tres los puntos de vista que los procuradores adoptaron para enfocar el tema: la tipología del derecho que se quería introducir, el concepto de libertad religiosa que habría de fundamentarlo y, por último, las razones que podían justificar su limitación.

\footnotetext{
36 Archivo del Congreso de los Diputados (ACD), Serie General-Comisión de Leyes Fundamentales y Presidencia del Gobierno, 4.907.

37 Ibidem.
} 
En cuanto al primer planteamiento, la Ponencia había recogido la sugerencia del Sr. Blas Piñar, que pedía definir el derecho a la libertad religiosa como un derecho civil. Más que secundar a los falangistas, la Ponencia quería simplemente subrayar el carácter pre-estatal de los derechos naturales del hombre. Como explicaba Herrero Tejedor, las expresiones «el Estado español reconoce la libertad religiosa como un derecho» $\mathrm{y}$ «el Estado español reconoce el derecho a la libertad religiosa» 38 no tenían el mismo valor semántico. De hecho, sólo la segunda respondía perfectamente al objetivo de compatibilizar libertad religiosa y confesionalidad de Estado ya que no sólo traducía mejor el espíritu de la Dignitatis humanæ reflejando adecuadamente la esencia democrática de aquella libertad, sino que dejaba abierta la puerta para una futura separación entre Estado e Iglesia.

Sería durante el debate sobre el concepto de libertad religiosa que debía sustentar el homónimo derecho cuando los falangistas tomaran otra vez la palabra, para recordar que no se podía prescindir de los derechos ya adquiridos por la Iglesia católica. Significativa, al respecto, sería la intervención del Sr. Escobar Kirkpatrick sosteniendo que, para ajustar el contenedor civil de la libertad religiosa al contenido teológico de la tolerancia, era suficiente respetar el derecho del hombre a profesar un credo diferente del suyo. Una vez más la Ponencia hacía oídos sordos, cerrando filas alrededor de un concepto de libertad religiosa menos restrictivo que contemplara también el derecho a no ser impedido a profesar un credo diferente del mayoritario39.

No menos tenso sería - por último - el debate acerca de las limitaciones al ejercicio del derecho a la libertad religiosa, encallándose en el concepto de bien público que había que emplear al respecto. La principal preocupación del sector duro del franquismo era que el derecho a la libertad religiosa se utilizara como cobijo para la defensa de los derechos políticos. Razón por la que los procuradores falangistas se apoyaban en el párrafo de la Dignitatis humanæe que reconocía la autoridad del Estado para reducir el radio de acción del derecho a la libertad religiosa frente a posibles abusos del mismo. Al hacerlo, sin embargo, habían omitido toda referencia al hecho de que el Estado no podía

\section{Ibidem. \\ 39 Ibidem.}


utilizar dicha discrecionalidad «de forma arbitraria o favoreciendo injustamente una parte»40. En vano el Sr. Blas Piñar había considerado iguales el concepto de bien común de la declaración conciliar y el del Fuero de los Españoles para justificar eventuales restricciones al derecho civil a la libertad religiosa, porque el Sr. Herrero Tejedor le había cortado el paso explicándole que en el Fuero de los Españoles la función del bien común era la de aglutinar los intereses de todos los españoles y no la de ordenar los derechos fundamentales del hombre. El subsecretario del Ministerio de Justicia y los Sres. Martínez Esteruela y Reyes Morales intervinieron entonces para asegurar de una vez por todas que, tanto el espíritu como la letra del proyecto que se estaba analizando, impedían categóricamente la entrada del pluralismo político por la puerta falsa de la libertad religiosa. Como se habían esmerado en explicar, el fin último de la Ley Orgánica reguladora del derecho a la libertad civil en materia religiosa no era otro que el de amparar exclusivamente los derechos de las confesiones minoritarias, debidamente reconocidas por la autoridad competente.

La discusión sobre la compatibilidad entre un derecho civil a la libertad religiosa para los no católicos y la confesionalidad del Estado ponía sobre la mesa también otro tema de envergadura para el régimen: el Concordato con la Santa Sede. El Sr. Mateu de Ros - portavoz de los que veían con recelos los trastornos producidos en España por el concilio Vaticano II - no había perdido la ocasión para plantear la conveniencia de revisar el especial reconocimiento que se le había otorgado a la Iglesia católica en 1953, o bien a través de una nueva norma legal o bien a través de un nuevo concordato. Señal más evidente del resurgimiento de un anticlericalismo de derecha, la cuestión no dejaba de preocupar tanto a la Santa Sede como al propio Estado: la primera, porque volvía a plantearse el dilema entre laicismo y nacionalcatolicismo que había tenido que solucionar entre 1936 y 1953; el segundo, porque la clase dirigente era consciente de que una ruptura con la Iglesia católica significaba - ahora más que nunca - romper las cadenas que ataban la sociedad al régimen. La solución radicaba en proceder gradualmente al desmantelamiento de la estrecha vinculación entre Iglesia y Estado que había caracterizado la vida política

URL:

<http://www.vatican.va/archive/hist_councils/ii_vatican_council/documents/vat-

ii_decl_19651207_dignitatis-humanae_sp.html $>$ [consultado el 7 de mayo de 2013]. 
española desde la guerra civil, para implantar un régimen de separación que no implicara, del lado del Estado, la pérdida de apoyo por parte de la Iglesia y, del lado de la Iglesia, el compromiso estatal de legislar respetando los principios de la moral católica.

Una vez publicado el informe de la Cominsión de Leyes Fundamentales y Presidencia del Gobierno en el Boletín Oficial de las Cortes de 23 de mayo de 196741, la Ley Orgánica 44/1967 se aprobaba casi por unanimidad en la sesión plenaria de la Cortes del 26 de junio siguiente. Sobre el alcance efectivo del derecho que se les otorgaba a los no católicos y, sobre todo, sobre el contenido político que se le asignó a la libertad religiosa en España, son suficientemente elocuentes las palabras pronunciadas por el Ministro de Justicia al terminar la votación:

toda libertad entraña el peligro de que los hombres la prostituyamos. Por eso la libertad ha de ser siempre responsable, es decir, ha de moverse dentro de un ámbito, con límites clara y vigorosamente trazados ${ }^{42}$.

La institucionalización de un derecho limitado a la libertad religiosa para los no católicos no intervino en el proceso de revisión concordataria que tendría lugar en el último lustro del franquismo. Como es sabido, la negativa de Franco a acatar la doctrina conciliar renunciado a su privilegio de presentación de obispos, fue lo que había puesto en tela de juicio el Concordato de 1953. Pero sí, habría de jugar un papel importante en la fase de transición constitucional que comenzaría tras el fallecimiento de Franco en noviembre de 1975 y la aprobación de la Ley para la Reforma Política en diciembre del año siguiente, sentando las bases para una eventual separación del Estado y la Iglesia. Por otro lado, no hay que olvidar que la redacción y el debate de los artículos 16 y 27 de la Constitución española de 1978, así como la negociación del acuerdo parcial sobre enseñanza, que España firmaría con la Santa Sede en enero de 1979, se llevaron a cabo estando todavía en vigor la Ley Orgánica de 1967.

${ }^{41}$ Boletín Oficial de las Cortes Españolas, 964/1967.

42 Boletín Oficial de las Cortes Españolas, 971/1967, p. 20.777. 


\section{* El autor}

Romina De Carli es licenciada en historia contemporánea por la Università degli Studi di Trieste en 1999, hizo sus estudios de doctorado en la Universidad Complutense de Madrid, doctorándose en 2007 bajo la dirección de Elena Hernández Sandoica. Las relaciones EstadoIglesia en España y la acción internacional de la Santa Sede, son unas de sus principales líneas de investigación. Se ha beneficiado de varias becas predoctorales (UCM en 2002-2006 y del Ministerio italiano de Asuntos Extranjero en 2000) y postoctorales (José Castillejo en 2013), además de haber sido investigador Marie Curie en 2004-2005. Ha participado en varios congresos y seminarios, tanto en España como en Alemania, Francia, Italia y Gran Bretaña. Entre sus publicaciones se destaca el libro El derecho a la libertad religiosa en la transición democrática de España (Madrid, CEPC, 2009), y su participación en varias obras colectivas. URL: < http://www.studistorici.com/progett/autori/\#DeCarli >

\section{Per citare questo articolo:}

DE CARLI, Romina, «De la confesionalidad a la tolerancia: del derecho civil a la libertad religiosa en la España del último franquismo», Diacronie. Studi di Storia Contemporanea : Spazi, percorsi e memorie, 29/10/2013,

URL:<http://www.studistorici.com/2013/10/29/decarli_numero_15/ >

Diacronie Studi di Storia Contemporanea $\beta$ www.diacronie.it

Risorsa digitale indipendente a carattere storiografico. Uscita trimestrale.

redazione.diacronie@hotmail.it

Comitato di redazione: Marco Abram - Jacopo Bassi - Luca Bufarale - Alessandro Cattunar - Elisa Grandi - Deborah Paci - Fausto Pietrancosta - Matteo Tomasoni - Luca Zuccolo

Diritti: gli articoli di Diacronie. Studi di Storia Contemporanea sono pubblicati sotto licenza Creative Commons 2.5. Possono essere riprodotti a patto di non modificarne i contenuti e di non usarli per fini commerciali. La citazione di estratti è comunque sempre autorizzata, nei limiti previsti dalla legge. 